\title{
Autologous TriMix-DC Melanoma Vaccine
}

National Cancer Institute

\section{Source}

National Cancer Institute. Autologous TriMix-DC Melanoma Vaccine. NCI Thesaurus.

Code C90560.

A dendritic cell vaccine consisting of dendritic cells (DCs) electroporated with mRNA encoding three adjuvants, CD40 lig and (CD40L), a constitutively active TLR4, and CD70 (all together termed T riMix); coelectroporated with full-length mRNA encoding MAGE-A3, MAGE-C2, Tyrosinase and gp100; and linked to DC-LAMP, with potential immunostimulating activity. Upon vaccination, the DCs may stimulate the immune system to mount an antigen-specific cytotoxic T-lymphocyte $(C T L)$ response against the melanoma antigens. This may decrease cellular proliferation of melanoma cells expressing these antigens. Electroporation with the adjuvants CD40L and TLR4 allows for the generation of mature and active DCs; electroporation with CD70 provides a costimulatory signal to CD27+ naive T cells thereby supporting T-cell proliferation and inhibiting T-cell apoptosis. 